\title{
Variation of Peak Temperature With Heating Rate in Differential Thermal Analysis
}

\author{
Homer E. Kissinger
}

\begin{abstract}
In differential thermal analysis, the temperature at which the maximum deflection is observed varies with heating rate for certain types of reactions. An expression can be derived relating this variation with the kinetics of the reaction. By making a number of differential thermal patterns at different heating rates, the kinetic constants can be obtained directly from the differential thermal data.

Measurements of the variation of peak temperature with heating rate have been made for several minerals of the kaolin group, the values of the kinetic constants determined, and these values compared with corresponding values obtained for both the same samples and similar material by conventional isothermal techniques. Some factors affecting the results are discussed.
\end{abstract}

\section{Introduction}

The method of differential thermal analysis (D'TA) has been universally accepted by mineralogical laboratories as a rapid and convenient means for recording the thermal effects that occur as a sample is heated. Changes in heat content of the active sample are indicated by deflections shown by a line representing the differential temperature. It is conventional to represent an endothermic effect by a negative deflection and an exothermic effect by a positive deflection. The deflections, whether positive or negative, are called peaks.

The factors responsible for the size, shape, and position of the resulting peaks are not well understood. Often the temperature of maximum deflection, or peak temperature, is considerably higher than the known transition or decomposition temperature of the substance. The peak temperature is also markedly affected by changes in technique [1]. ${ }^{1} \quad$ Only in the case of crystalline inversions (transitions occurring instantaneously at a fixed temperature), has there been a satisfactory explanation of the D'TA peaks [2].

The work of Murray and White $[3,4,5]$ on the kinetics of decomposition of clay minerals can be applied to the interpretation of the D'TA patterns of these materials. These workers measured the rates of isothermal dehydration of clays, calculated the kinetic constants of the materials, and from these data constructed curves of reaction rate versus time for constant heating rates. These artificial curves were similar in shape to D'TA curves, the temperatures of maximum reaction rate were very close to the peak temperatures observed in D'TA, and these temperatures varied in the same manner with heating rate for both the calculated and the observed curves. Later Sewell [6] found that the peak temperatures of D'TA patterns made at different heating rates were predicted fairly closely by the equation of Murray and White.

According to the equation derived by Murray and White, the temperature of maximum deflection is defined by the kinetic constants of the material and

\footnotetext{
1 Figures in brackets indicate the literature references at the end of this paper.
}

the heating rate. The assumption that the peak temperature occurs when the reaction rate is a maximum is supported by the experimental work described above. It should then be possible to calculate the kinetic constants directly from D'TA data by making a number of patterns at different heating rates. The series of experiments to be described was performed to verify the equation of Murray and White and to apply it to the determination of kinetic constants from DTA data.

\section{Preliminary Theory}

Murray and White [3] and Vaughan [7] reported that the thermal decomposition of clays obeyed a first-order law. At constant temperature,

$$
\left(\frac{\partial x}{\partial t}\right)_{T}=k_{T}(1-x)
$$

where $x$ is the fraction of material decomposed. The magnitude of the rate constant, $k_{T}$, is determined by the temperature and is given by the Arrhenius equation

$$
k_{T}=A e^{-\frac{E}{R T}}
$$

where $R$ is the gas constant, $T$ is the Kelvin temperature, and $A$ and $E$ are constants that are properties of the material. The constant $E$, called the activation energy, is often interpreted as the energy barrier opposing the reaction. The constant $A$, most often called the frequency factor, is a measure of the probability that a molecule having energy $E$ will participate in a reaction.

When the temperature is changing with time, the reaction rate is

$$
\frac{d x}{d t}=\left(\frac{\partial x}{\partial t}\right)_{T}+\left(\frac{\partial x}{\partial T}\right)_{t} \frac{d T}{d t} .
$$

The rate of change of $x$ with temperature, with the time coordinate fixed, $(\partial X / \partial T)_{t}$ is zero, because fixing the time also fixes the number and position of the 
particles constituting the system. The only effect of an instantaneous change in temperature is in the velocity of thermal motion of the particles. The total rate of reaction may then be expressed,

$$
\frac{d x}{d t}=A(1-x) e^{-\frac{E}{R T}} .
$$

This expression holds for any value of $T$, whether constant or variable, so long as $x$ and $T$ are measured at the same instant.

When the reaction rate is a maximum, its derivative with respect to time is zero. Solving eq (4) for $(d / d t)(d x / d t)$ :

$$
\frac{d}{d t}\left(\frac{d x}{d t}\right)=\frac{d x}{d t}\left(\frac{E}{R T^{2}} \frac{d T}{d t}=A e^{-\frac{E}{R T}}\right) .
$$

The maximum value of $d x / d t$ occurs at temperature $T_{m}$, defined by

$$
A e^{-\frac{E}{R T_{m}}}=\frac{E}{R T_{m}^{2}} \frac{d T}{d t}
$$

This is the equation derived by Murray and White [5].

From eq (6) it is easily seen that

$$
\frac{d\left(\ln \frac{\phi}{T_{m}^{2}}\right)}{d\left(\frac{1}{T_{m}}\right)}=-\frac{E}{R},
$$

where $\phi=d T / d t$, the"heatingrrate.

\section{Experimental Procedure}

\subsection{Materials}

The clay minerals of the kaolin group have been the predominant materials used in previous studies of the relation of chemical kinetics and DTA. For this reason, tbis group has been used in the present study.

Three kaolinite samples, designated A, B, and C, were chosen. Kaolinite A was a Florida kaolinite, whereas $\mathrm{B}$ and $\mathrm{C}$ were from Georgia. Examination with the electron microscope showed that kaolinites $\mathrm{B}$ and $\mathrm{C}$ consisted of well formed hexagonal plates with sharply defined edges. The particles of kaolinite A were smaller, thicker in proportion to their breadth, and less well defined in outline. Impurities were almost nonexistent in all three kaolinites. X-ray examination showed all three to be well crystallized, with very little $b$-axis disorder of the type described by Brindley and Robinson [8].

Two samples of halloysite were chosen, one from Eureka, Utah, and one from Bedford, Ind. These materials were described by Kerr and Kulp [9]. The Indiana material was designated by the symbol $\mathrm{H}-12$, the Eureka material by H-13. This identification was retained for the present study. Both halloysites contained appreciable amounts of impurities, principally gibbsite and quartz.

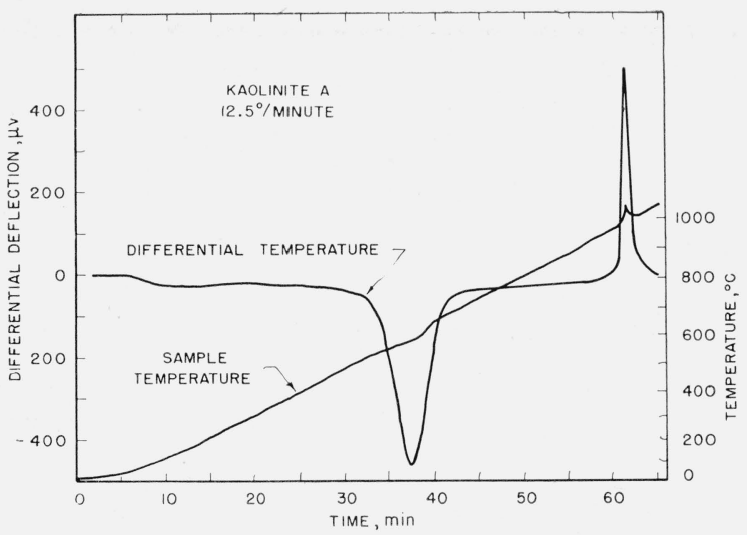

FiguRE 1. A typical differential-thermal-analysis pattern of a kaolinite clay.

The endothermic peak in the region $500^{\circ}$ to $700^{\circ} \mathrm{C}$ results from the loss of hydroxyl groups from the structure. The position, and the height, of the peak vary with heating rate.

\subsection{Apparatus and Procedure}

The differential-thermal-analysis apparatus used in this work consists of a vertical platinum-wound furnace and the associated controlling and recording equipment. Specimen holders are platinum tubes, made of 20-mil Pt sheet. Two sizes of specimen holders are available, one pair being $3 / 8$ in. in diameter by $1 \frac{1}{4} \mathrm{in}$. long, the other $1 / 8 \mathrm{in}$. in diameter and $1 / 2 \mathrm{in}$. long. Platinum-platinum 10-percent-rhodium thermocouples made of 15 -mil wire are used.

The furnace temperature is controlled by a camdriven program controller. A current interrupter in the cam-motor circuit allows any heating rate up to about $25 \mathrm{deg} \mathrm{C} / \mathrm{min}$ to be selected by the operator.

The differential temperature is measured between the centers of the active and the reference sample. The reference material is $\alpha$-aluminum oxide. The sample temperature and the differential temperature are recorded on the same chart by a multipoint recorder. A typical pattern is shown in figure 1.

Each of the five sample materials was run in DTA in the $3 / 8$-in. holders at about $3,4.5,6,10,12.5$, and $20 \mathrm{deg} \mathrm{C} / \mathrm{min}$. The $20 \mathrm{deg} / \mathrm{min}$ rate was not used with the $1 / 8$-in. holders.

Isothermal weight-loss determinations were made with the NBS recording analytical balance [10]. A platinum crucible, suspended in the furnace from one side of the balance, contains the sample. The loss in weight is recorded continuously while the furnace temperature is held constant. In the present study, weight-loss determinations were made at $450^{\circ}$, $500^{\circ}, 550^{\circ}$, and $600^{\circ} \mathrm{C}$ for each material. Approximately $1 \mathrm{~g}$ of sample was used for each determination. Reaction-rate constants were calculated at each temperature by the method described by Murray and White [3]. Kinetic constants were then calculated by graphical solution of eq (2).

\section{Results and Discussion}

The isothermal weight-loss data verified the firstorder law (eq 1) for the three kaolinites. The halloysite decomposition did not obey the first-order 


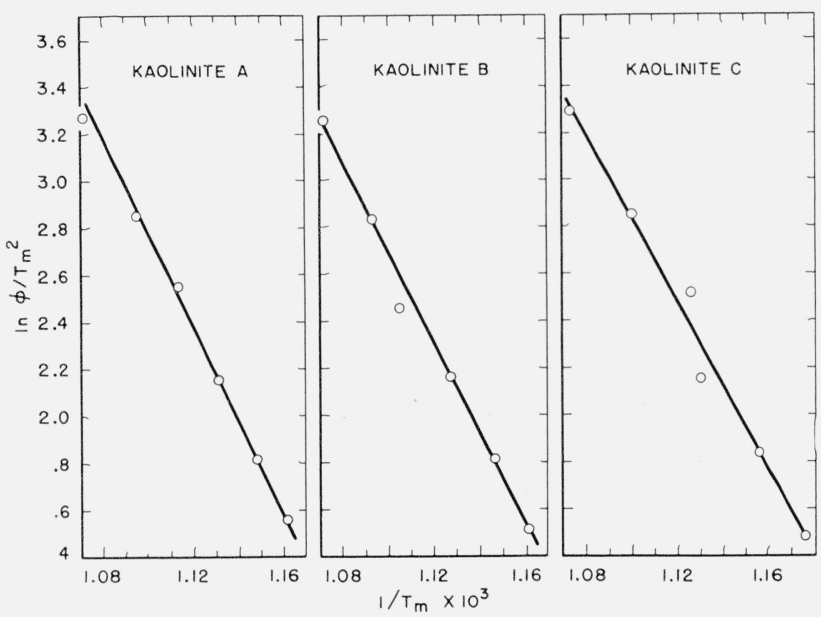

Figure 2. Differential-thermal-analysis data obtained for the kanlinites in the $3 / 8$-in. specimen holder, plotted to determine $E / R$.

equation at the higher temperatures. Although other workers [3, 7] have reported that halloysite decomposes according to the first-order law, the present work indicates that this is true only at low temperatures and low reaction rates. Trial-anderror attempts to determine the reaction order were but partially successful, indicating that the order became less than unity at more rapid reaction rates.

Activation energies and frequency factors were calculated for the kaolinites from the isothermal data. It was not possible to obtain these constants from the data for the halloysites. The values of $A$ and $E$ for the kaolinites are given in table 1 . Some values reported by other workers are shown for comparison.

The values of $A$ and $E$ for kaolinite vary from sample to sample. In general, the well-crystallized kaolinites have activation energies in the range 38 to $45 \mathrm{kcal} / \mathrm{mole}$, whereas the less well ordered forms, the fireclays, give values of $E$ down to $30 \mathrm{kcal} / \mathrm{mole}$ or less. Halloysite, with the same composition and only slightly different in structure from kaolinite, is reported $[3,7]$ to have activation energies slightly lower than those of well-crystallized kaolinites.

TABLE 1. Values of activation energy $E$ and frequency factor $A$ determined isothermally for kaolin minerals

\begin{tabular}{|c|c|c|c|}
\hline Source & Material & $E$ & $\log _{10} A$ \\
\hline Present work & $\left\{\begin{array}{l}\text { Kaolinite A } \\
\text { Kaolinite B } \\
\text { Kaolinite C }\end{array}\right.$ & $\begin{array}{r}k c a l / m o l e \\
42.06 \\
37.20 \\
38.81\end{array}$ & $\begin{array}{l}\text { 8. } 66 \\
6.86 \\
7.10\end{array}$ \\
\hline Murray and White [4] - & $\left\{\begin{array}{l}\text { Supreme kaolin } \\
\text { K. plastic kaolin } \\
\text { Newton Abbot } \\
\text { Raw bottle clay } \\
\text { Eureka halloysite. }\end{array}\right.$ & $\begin{array}{l}44.83 \\
36.69 \\
40.66 \\
38.99 \\
36.74\end{array}$ & $\begin{array}{l}9.07 \\
6.96 \\
7.98 \\
7.56 \\
6.90\end{array}$ \\
\hline Vaughan $[7]$ & $\left\{\begin{array}{l}\text { China clay 1. } \\
\text { China clay } 2 \\
\text { Fireclay 1 } \\
\text { Fireclay 2 } \\
\text { Halloysite }\end{array}\right.$ & $\begin{array}{l}40.61 \\
38.10 \\
25.75 \\
26.30 \\
34.90\end{array}$ & $\begin{array}{l}\text { 9. } 83 \\
9.26 \\
6.01 \\
\text { 6. } 26 \\
\text { 8. } 45\end{array}$ \\
\hline
\end{tabular}

In differential thermal analysis, the temperature at which the peak deflection occurs for a given heating rate is determined by both $A$ and $E$ (eq 6$)$. If the heating rate is changed, the peak temperature is changed. The variation of peak temperature with heating rate is governed only by the activation energy, $E$ (eq 7). Plotting ln $\phi / T_{m}^{z}$ versus $1 / T_{m}$, as indicated by eq (7), should give a straight line of slope $-E / R$.

The results of the DTA experiments with the $3 / 8$ in. holders are given in table 2 , a. It was found that reproducibility of peak temperatures at a given heating rate was improved by loading the sample loosely into the holder, with no packing other than gentle tapping around the outside of the holder. The standard deviation of an individual measurement was found to be $2.6 \mathrm{deg} \mathrm{C}$, calculated from 25 pairs of duplicate determinations [11]. The data for the three kaolinites, plotted as indicated by eq (7), is shown in figure 2 .

The slope of the line and the standard deviation of the points about the line are readily calculated [11]. For purposes of calculation, $1 / T_{m}$ was taken as the dependent variable. The standard deviation in $1 / T_{m}$ was converted to a standard deviation in $T_{m}$ by the relation $\Delta(1 / T)=\Delta T / T^{2}$, taking $T$ as $800^{\circ}$ $K$. The standard deviations of the observed peak temperatures from the predicted temperatures are: for kaolinite A, $2.2 \operatorname{deg}$ C; kaolinite B, $2.0 \operatorname{deg}$ C; kaolinite $\mathrm{C}, 3.7 \mathrm{deg} \mathrm{C}$; halloysite $\mathrm{H}-12,1.3 \mathrm{deg} \mathrm{C}$ ? and halloysite $\mathrm{H}-13,1.0 \mathrm{deg} \mathrm{C}$. These values are equal within acceptable limits to the standard deviation of a single determination, $2.6 \mathrm{deg} \mathrm{C}$.

The slopes of the lines are used to determine the energy of activation, $E$. When $E$ is known, $A$ can be calculated from eq (6). The values of $A$ and $E$ determined in this manner are given in table 3.

The values of $E$ determined by this method are from 3 to 8 percent lower than those determined isothermally. The values of $\log _{10} A$ are also lower.

TABLE 2. Differential-thermal-analysis measurements

\begin{tabular}{|c|c|c|c|c|c|}
\hline \multirow{2}{*}{$\begin{array}{c}\text { Heating rate, a } \\
\qquad \phi\end{array}$} & \multicolumn{5}{|c|}{ Peak temperature } \\
\hline & A & B & $\mathrm{C}$ & $\mathrm{H}-12$ & $\mathrm{H}-13$ \\
\hline \multicolumn{6}{|c|}{ a. 3/8-in. holders } \\
\hline $\begin{array}{c}\operatorname{deg} \mathrm{C} / \mathrm{min} \\
20 \\
12.5 \\
10 \\
6 \\
4.5 \\
3\end{array}$ & $\begin{array}{l}{ }^{\circ} \mathrm{C} \\
660 \\
640 \\
625 \\
611 \\
598 \\
588\end{array}$ & $\begin{array}{l}{ }^{\circ} \mathrm{C} \\
665 \\
642 \\
632 \\
614 \\
599 \\
584\end{array}$ & $\begin{array}{l}{ }^{\circ} \mathrm{C} \\
659 \\
635 \\
615 \\
611 \\
592 \\
574\end{array}$ & $\begin{array}{l}{ }^{\circ} \mathrm{C} \\
641 \\
629 \\
616 \\
603 \\
588 \\
582\end{array}$ & $\begin{array}{c}{ }^{\circ} C \\
640 \\
629 \\
614 \\
597 \\
583 \\
568\end{array}$ \\
\hline \multicolumn{6}{|c|}{ b. $1 / 8$-in. holders } \\
\hline $\begin{array}{l}12.5 \\
10 \\
6 \\
4.5 \\
3\end{array}$ & $\begin{array}{l}557 \\
549 \\
537 \\
525 \\
514\end{array}$ & $\begin{array}{l}563 \\
553 \\
538 \\
528 \\
523\end{array}$ & $\begin{array}{l}544 \\
530 \\
520 \\
511 \\
499\end{array}$ & $\begin{array}{l}553 \\
547 \\
530 \\
519 \\
512\end{array}$ & $\begin{array}{l}553 \\
542 \\
533 \\
517 \\
508\end{array}$ \\
\hline
\end{tabular}

aHeating rates given are nominal values. The actual rates were measured individually for each pattern and varied slightly from pattern to pattern. 
TABLE 3. Values of activation energy $E$ and frequency factor $A$ determined by differential-thermal-analysis method

\begin{tabular}{|c|c|c|c|c|}
\hline \multirow{2}{*}{ Material } & \multicolumn{2}{|c|}{ In $3 / 8$-in. holder } & \multicolumn{2}{|c|}{ In $1 / 8$-in. holder } \\
\hline & $E$ & $\log _{10} A$ & $E$ & $\log _{10} A$ \\
\hline $\begin{array}{l}\text { Kaolinite A } \\
\text { Kaolinite B } \\
\text { Kaolinite C } \\
\text { Halloysite } \mathrm{H}-12 \\
\text { Halloysite } \mathrm{H}-13\end{array}$ & $\begin{array}{c}\mathrm{kcal} / \mathrm{mole} \\
38.83 \\
36.00 \\
34.97 \\
38.01 \\
36.10\end{array}$ & $\begin{array}{l}7.05 \\
6.28 \\
6.11 \\
6.91 \\
6.49\end{array}$ & $\begin{array}{c}k c a l / \text { mole } \\
40.91 \\
35.98 \\
35.79 \\
38.07 \\
35.85\end{array}$ & $\begin{array}{l}8.54 \\
7.14 \\
7.33 \\
7.82 \\
7.22\end{array}$ \\
\hline
\end{tabular}

This discrepancy may be due to the temperature gradient across the sample. The thermocouple at the center of the sample indicates a temperature different from that of the bulk of the sample. To reduce this temperature difference to a minimum, samples of the kaolinites were diluted 1:4 with $\alpha-\mathrm{Al}_{2} \mathrm{O}_{3}$. When the DTA results were plotted, it was found that in some cases the points fitted a straight line, but that activation energies much larger than those found for the undiluted samples were indicated. For kaolinite $\mathrm{C}$, figure 3, the standard deviation of the points from a straight line was $11 \mathrm{deg} \mathrm{C}$, much too large to be accounted for by the experimental error.

In a further attempt to reduce the temperature difference between the center and the bulk of the sample, the experiments were repeated with undiluted samples, using the 1/8-in. specimen holders. Reproducibility was about the same as for the larger

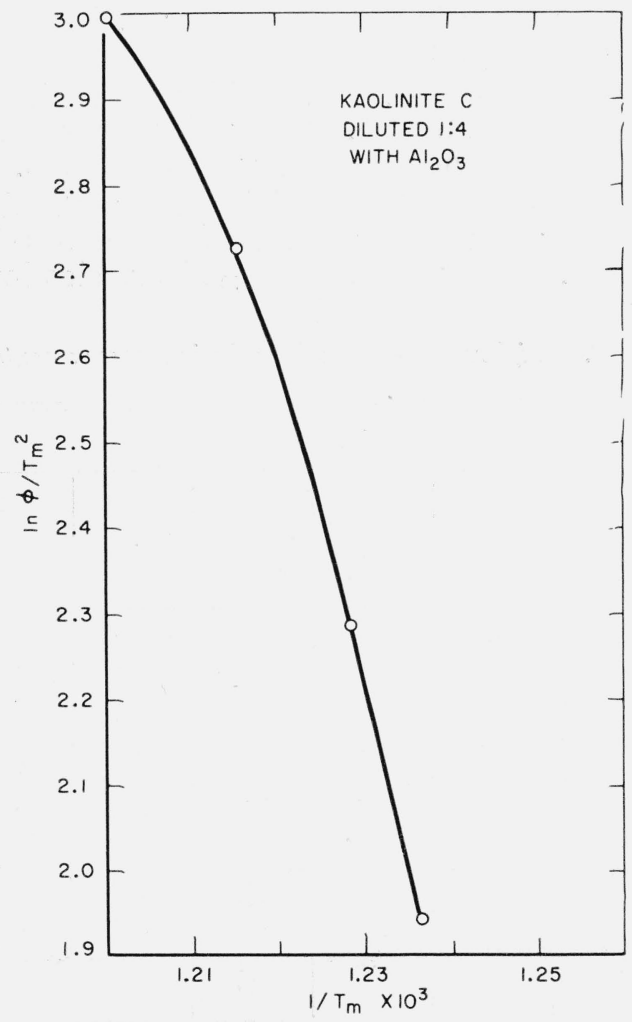

Figure 3. Differential-thermal data for a specimen containing a 1:4 mixture of clay and alumina. holders, the standard deviation being $2.2 \mathrm{deg}$ C. The results obtained at the $20 \mathrm{deg} \mathrm{C} / \mathrm{min}$ rate were occasionally erratic, the decomposition proceeding so rapidly that some of the powdered sample was forced from the holder. This was not observed to occur with the larger holders.

Results of DTA measurements using the smaller holders are given in table $2, \mathrm{~b}$. The peak temperatures are from 60 to $80 \mathrm{deg}$ C lower than those obtained at corresponding heating rates in the large holders. An undetermined part of this difference is the result of the modifications to the thermocouple assembly necessary to accommodate the smaller holders. Calculated as before, the standard deviations were, for the five samples, $1.2,1.9,1.6,2.5$, and $2.4 \mathrm{deg} C$. The values of $E$ and $A$ obtained from these data are given in table 3 .

In table 3 it can be seen that the values of $E$ are only slightly different, for data obtained with the two specimen-holder sizes. The values of $E$ obtained by the D'TA method are somewhat lower than those determined isothermally, however, whereas the values of $\log _{10} A$ obtained with the $1 / 8$-in. holder are virtually identical with the isothermal values.

The approximate precision of the D'TA method can be calculated. In the present case, the standard deviation of a single measurement is $2.2 \mathrm{deg} \mathrm{C}$. The order of magnitude of the quantities encountered is $40 \mathrm{kcal}$ for $E$ and $800^{\circ} \mathrm{K}$ for $T_{m}$. For the five heating rates used with the $1 / 8$-in. holders (table 2 ), the standard deviation in $E$ is about $2.4 \mathrm{kcal}$. The value of $\log _{10} A$ depends on the magnitude of the peak temperature, which varies with the technique used.

Setting confidence limits equal to twice the standard deviation, this method of determining $E$ should give values within $\pm 5 \mathrm{kcal}$, or about 12 percent, for five heating rates between 3 and $12 \frac{1}{2} \mathrm{deg}$ $\mathrm{C} / \mathrm{min}$. Considering the narrow range of temperature that is used, it is not surprising that this method is no more precise. The agreement of the D'TA results with the isothermal results, within the limits of precision, is considered confirmation that, for reactions that proceed at a rate varying with temperature, eq (7) correctly describes the variation of peak temperature with heating rate in differential thermal analysis. The lack of agreement in the case of diluted samples can not be explained. The same effect was observed by Sewell [6], who attributed the discrepancy to variations in the partial pressure of the evolved gas within the reacting sample.

\section{References}

[1] J. A. Pask and M. F. Warner, Differential thermal analysis methods and techniques, Bul. Am. Ceram. Soc. 33, 168-175 (1954).

[2] H. T. Smyth, Temperature distribution during mineral inversion and its significance in differential thermal analysis, J. Am. Ceram. Soc. 34, 221-224 (1951).

[3] P. Murray and J. White, Kinetics of the thermal dehydration of clays, Trans. Brit. Ceram. Soc. 48, 187-206 (1949).

[4] P. Murray and J. White, Kinetics of the thermal decomposition of clay. 2. Isothermal decomposition of clay minerals, Trans. Brit. Ceram. Soc. 54, 151-187 (1955). 
[5] P. Murray and J. White, Kineties of the thermal decomposition of clay. 4. Interpretation of the differential thermal analysis of clays, Trans. Brit. Ceram. Soc. 54, 204-237 (1955).

[6] E. C. Sewell, The consequences for differential thermal analysis of assuming a reaction to be first order, Clay Minerals Bul. 2, 233-241 (1955).

[7] F. Vaughan, Energy changes when kaolin minerals are heated, Clay Minerals Bul. 2, 265-274 (1955).

[8] G. W. Brindley and K. Robinson, Randomness in the structures of kaolinitic clay minerals, Trans. Faraday Soc. 42b, 198-205 (1945).
[9] P. F. Kerr and J. L. Kulp, Reference clay localities: United States, Prelim. Rep. No. 2, Am. Petroleum Inst. Proj. 49, Columbia Univ. (1949).

[10] F. A. Mauer, An analytical balance for recording rapid changes in weight, Rev. Sci. Inst. 25, 598-602 (1954).

[11] W. J. Youden, Statistical methods for chemists, p. 45 (John Wiley \& Sons, Inc., New York, N. Y., 1951).

Washington, June 8, 1956. 